\title{
Global Risk Diversification: An Empirical Investigation From The U. S. Perspective
}

\author{
H. Christine Hsu, California State University, Chico, USA
}

\begin{abstract}
The case for global risk diversification has been built on correlations between the U.S. and international stock markets. Now that we witness how tightly the world stock markets are correlated, especially after the global financial crisis of 2008-2009, does it still make sense to diversify globally? Can the investments in global equity portfolios be protected in today's volatile markets? These questions have preoccupied a growing number of portfolio managers in recent years, as well as many of us who invest in stock markets. Since gold/silver and bonds tend to move inversely with the stock markets, a hedging strategy of combining them with stock portfolios should protect the equity investments during global market downturns. The study explores the risk-return profiles of various global portfolios and provides insights about the extent to which the U.S. investors need to allocate their investments in Asia/Pacific, European stock markets, and across other investment vehicles, such as gold/silver and bonds. The findings from this research have practical implications for both investors and portfolio managers interested in going global.
\end{abstract}

Keywords: international equity diversification; global portfolios

\section{INTRODUCTION}

n an early benchmark study on risk diversification, Solnik (1974) documents substantial gains from combining US and European stocks; in terms of variability of returns, a well-diversified international equity portfolio is half as risky as a well-diversified US equity portfolio. This is consistent with the modern portfolio theory pioneered by Markowitz (1952) which states that combining two assets with less-thanperfect correlation reduces the portfolio risk, as measured in terms of standard deviation, without necessarily lowering the portfolio return. This theory is applied widely in practice to construct some very popular global equity portfolios, such as the various S\&P Global, FTSE and MSCI Sector/Region Index Funds, among others.

A large body of recent literature exists on the benefits of international equity diversification. To name a few, Fletcher and Marshall (2005) find significant diversification benefits for the U.K. investors moving from a domestic strategy to an international strategy that includes either global industry or country equity portfolios. Chang and Caudill (2006) provide evidence that long-run benefits exist for Taiwanese investors diversifying into the U.S. equity market over the period 1995-2001. Driessen and Laeven (2007) report that global diversification benefits exist for domestic investors in both developed and developing countries during the sample period 1985-2002. Chiou, Lee, Chang (2009) show that diversifying portfolios internationally is beneficial to the U.S. investors, even though financial markets are becoming more integrated. Gupta and Donleavy (2009) demonstrate that Australian investors can reduce their overall portfolio risk by diversifying into equities from other markets. Metghalchi and Adamchik (2009) present that the risk-return picture can be improved by mixing the S\&P Europe 350 index with each of the individual country indexes (Austria, Denmark, Spain, Sweden, and Switzerland). You and Daigler (2010) report that the benefits from international diversification are asymmetric, with reduced diversification benefits during bear markets.

The heart of Markowitz's theory focuses on the imperfect correlation between the two assets in question. The less the assets are correlated, the greater the benefit of risk diversification. In today's volatile global environment, with increasing interdependence among world stock markets, especially after the global financial crisis of 2008-2009, does it still make sense to diversify globally? Can the investments in global equity portfolios be 
protected in today's volatile markets? These questions have preoccupied a growing number of portfolio managers in recent years, as well as many of us who invest in stock markets.

The objective of this paper is to address these questions that are extremely relevant to most US investors. Since gold/silver and bonds tend to move inversely with the stock markets, a hedging strategy of combining them with stock portfolios should protect the equity investments, even during global market downturns.

The study explores the risk-return profiles of various global portfolios and provides insights about the extent to which the U.S. investors need to allocate their investments in Asia/Pacific/European equity markets and across other investment vehicles, such as gold/silver and bonds. The findings from this research have practical implications for both investors and portfolio managers interested in going global.

\section{DATA AND ANALYSIS}

The primary data used in this study are the index values for the major stock markets in Asia/Pacific, Europe, and the U.S., and the Gold/Silver sector index prices provided by the Commodity Systems, Inc. along with the historical returns of the investment grade corporate bond index fund (Bond) compiled by Black Rock Inc. The end of month index prices and foreign exchange (US dollar per unit of foreign currency) data are collected over the period from August 2002 through September 2010. The monthly closing prices used in the study are the prices adjusted for dividends and stock splits.

Table 1: Monthly Return Descriptive Statistics (August 2002-September 2010)

\begin{tabular}{|c|c|c|c|c|c|c|c|}
\hline \multicolumn{8}{|c|}{ Panel A: Monthly Return Descriptive Statistics for Various Stock Markets } \\
\hline Stock Market & Market Index & Mean & Median & SD & Minimum & Maximum & Count \\
\hline Australia & All Ordinaries & $1.24 \%$ & $2.30 \%$ & $6.25 \%$ & $-25.31 \%$ & $15.05 \%$ & 98 \\
\hline India & BSE 30 & $2.42 \%$ & $2.97 \%$ & $8.60 \%$ & $-24.26 \%$ & $30.51 \%$ & 98 \\
\hline Hong Kong & Hang Seng & $1.01 \%$ & $1.81 \%$ & $6.44 \%$ & $-22.39 \%$ & $17.08 \%$ & 98 \\
\hline Malaysia & KLSE Composite & $1.06 \%$ & $1.03 \%$ & $4.93 \%$ & $-16.69 \%$ & $16.24 \%$ & 98 \\
\hline South Korea & Seoul Composite & $1.37 \%$ & $1.52 \%$ & $8.04 \%$ & $-26.95 \%$ & $23.48 \%$ & 98 \\
\hline Japan & Nikkei 225 & $0.49 \%$ & $0.64 \%$ & $5.87 \%$ & $-21.47 \%$ & $11.80 \%$ & 98 \\
\hline China & Shanghai Composite & $1.12 \%$ & $1.63 \%$ & $9.10 \%$ & $-24.55 \%$ & $28.01 \%$ & 98 \\
\hline Singapore & Straits Times & $1.24 \%$ & $1.92 \%$ & $6.32 \%$ & $-25.41 \%$ & $22.03 \%$ & 98 \\
\hline Taiwan & Taiwan Weighted & $0.88 \%$ & $0.55 \%$ & $7.38 \%$ & $-20.59 \%$ & $17.56 \%$ & 98 \\
\hline Austria & ATX & $1.50 \%$ & $2.21 \%$ & $7.86 \%$ & $-30.66 \%$ & $16.06 \%$ & 98 \\
\hline Netherlands & AEX General & $0.54 \%$ & $1.57 \%$ & $7.39 \%$ & $-25.74 \%$ & $20.98 \%$ & 98 \\
\hline Switzerland & Swiss Market & $0.75 \%$ & $1.12 \%$ & $4.81 \%$ & $-11.27 \%$ & $16.89 \%$ & 98 \\
\hline France & CAC 40 & $0.65 \%$ & $1.51 \%$ & $6.48 \%$ & $-17.44 \%$ & $20.01 \%$ & 98 \\
\hline United Kingdom & FTSE 100 & $0.33 \%$ & $0.31 \%$ & $4.27 \%$ & $-12.03 \%$ & $9.32 \%$ & 98 \\
\hline Germany & DAX & $1.17 \%$ & $2.39 \%$ & $7.52 \%$ & $-25.38 \%$ & $29.13 \%$ & 98 \\
\hline United States & S\&P 500 & $0.34 \%$ & $1.09 \%$ & $4.59 \%$ & $-16.94 \%$ & $9.39 \%$ & 98 \\
\hline \multicolumn{8}{|c|}{ Panel B: Monthly Return Descriptive Statistics for Various Assets } \\
\hline Asset & Asset Index & Mean & Median & SD & Minimum & Maximum & Count \\
\hline Bond & $\begin{array}{l}\text { iShares iBoxx \$ Investment } \\
\text { Grade Corporate Bond }\end{array}$ & $0.56 \%$ & $0.74 \%$ & $2.28 \%$ & $-8.23 \%$ & $11.02 \%$ & 98 \\
\hline Gold/Silver & PHLX Gold/Silver & $1.78 \%$ & $1.38 \%$ & $10.60 \%$ & $-38.22 \%$ & $33.42 \%$ & 98 \\
\hline
\end{tabular}

Note: Return is the sum of dividend yield and capital gain or loss in US Dollar.

Table 1 contains the monthly return descriptive statistics for various stock markets (sectors) in Panel A (B). Panel A of Table 1 reveals that, with the exception of the United Kingdom, the stock markets in Asia/Pacific and Europe provide higher returns (with mean returns ranging from $0.49 \%$ in Japan to $2.42 \%$ in India) as well as higher risk (with standard deviation ranging from $4.81 \%$ in Switzerland to $9.1 \%$ in China) as compared to S\&P 500 (with mean return of $0.34 \%$ and standard deviation of $4.59 \%$ ) over the period from August 2002 to September 2010. Panel B of Table 1 shows that in comparison to S\&P 500 over the same period, both Bond and Gold/Silver portfolios yield higher returns, with mean return of $0.56 \%$ and $1.78 \%$, respectively, whereas Bond involves lower risk with standard 
deviation of $2.28 \%$ and Gold/Silver embodies much higher risk with $10.6 \%$ standard deviation. Without a doubt, of the three categories of investment vehicles, Bond is the least risky, Gold/Silver is the most risky, and equity is somewhere in between. Two questions arise: 1) Can investors holding S\&P 500 improve their investments' riskreturn profiles if diversifying into Asia/Pacific/European stock markets? and 2) Is it worthwhile to add Bond and/or Gold/Silver index funds to the equity portfolios in today's volatile global markets?

According to the modern portfolio theory, the diversification benefit exists if the two portfolios in question are not moving in lockstep. Rather than focusing on the correlation between the U.S. and each foreign stock market individually, the study examines the correlation between the U.S. and Portfolio Asia/Pacific/Europe (APE), an equally weighted Asia/Pacific (AP) and Europe stock portfolios, where Portfolio AP (Europe) consists of nine (six) equally weighted stock market indexes in Asia/Pacific (Europe); namely, Australia, India, Hong Kong, Malaysia, South Korea, Japan, China, Singapore, and Taiwan (Austria, Netherlands, Switzerland, France, United Kingdom, and Germany).

To gain a clear perspective on how S\&P 500 and each of the three portfolios (i.e., APE, Bond, and Gold/Silver) are correlated through time, the procedure of computing the 36-month rolling correlations in Solnik, Bourcrelle and Fur (1996) is implemented. That is, at the end of each month from July 2005 through September 2010, the correlations between two portfolios are derived based on the two portfolios' time-series returns for the previous 36 months. For example, in July 2005, the correlation is computed according to the two portfolios' pairreturns from August 2002 to July 2005; in August 2005, the correlation is computed according to the pair-returns from September 2002 to August 2005 and so on. The resulting 36-month rolling correlations between S\&P 500 and various portfolios are plotted against time in Figure 1, which shows that the correlation coefficient between S\&P 500 and Bond (Gold/Silver) ranges from -.17 (-.06) to .63 (.51) from July 2005 through September 2010.

It is interesting to witness how Bond and Gold/Silver portfolios are moving somewhat together with S\&P 500, especially after the global financial crisis of 2008-2009. In contrast, as might be expected, Figure 1 reveals a high degree of correlation between APE equity portfolio and S\&P 500, with the coefficient of correlation ranging from .75 to .89 over the same period. Nevertheless, the three portfolios in the study are not perfectly correlated with S\&P 500. Thus, all are potential candidates for US investors searching for the benefit of global diversification.

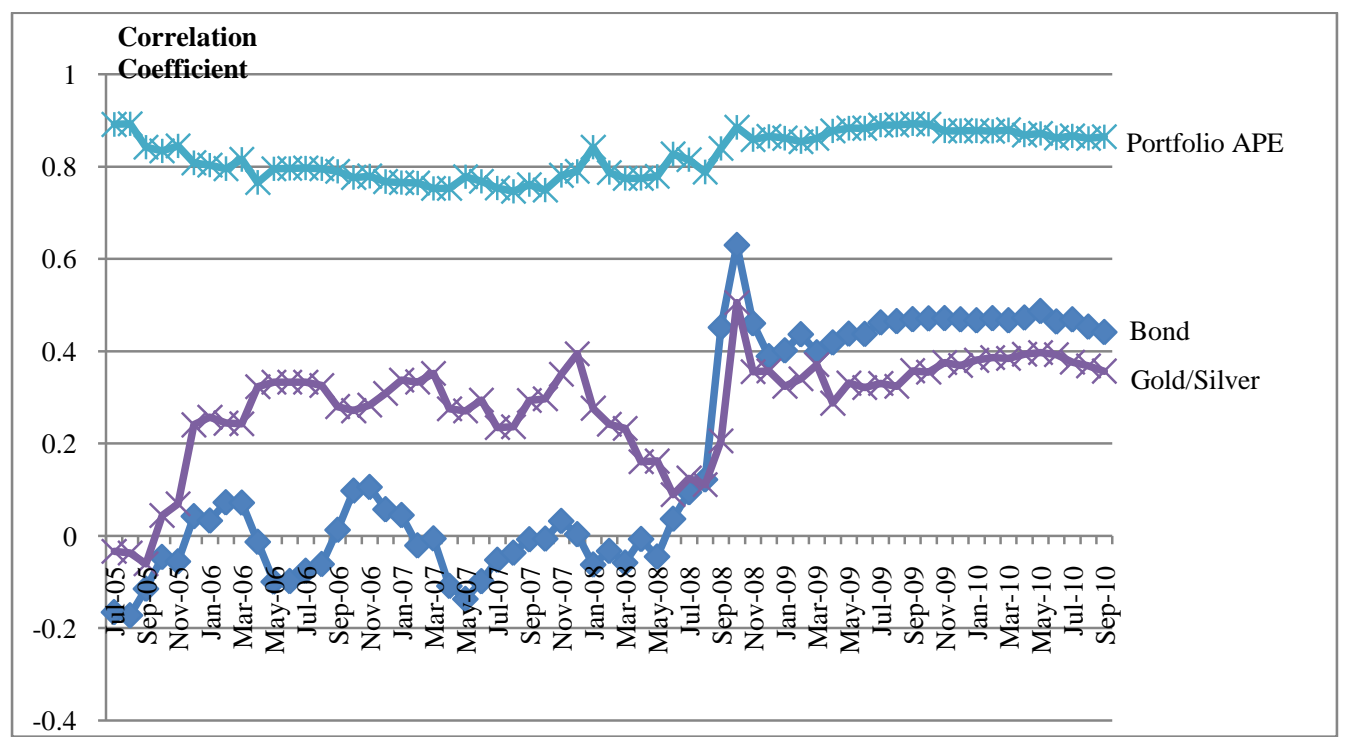

Figure 1: Rolling Correlations with S\&P 500 (July 2005-September 2010) 
In this study, S\&P 500 is used as the base portfolio in examining the risk-return tradeoffs of various global portfolios. As the 500 US stocks in the index are selected from different industry sectors, an investor holding S\&P 500 is considered well diversified in the U.S. market. In fact, many professionals in the investment community use the index as a benchmark when evaluating portfolio performances. Thus, to investigate the risk-return profiles of the stock portfolios from a US investor's perspective, the index is combined with APE portfolio to construct ten Global APE portfolios with varying S\&P 500 components $(0 \%, 10 \%, 20 \%, 30 \%, 40 \%, 50 \%, 60 \%, 70 \%, 80 \%$ and $90 \%)$. To investigate if the investments in the equity portfolios can be protected during global market downturns, the index is combined with APE, Bond and/or Gold/Silver portfolios to form thirty Global portfolios with varying S\&P 500 components $(0 \%, 10 \%, 20 \%, 30 \%, 40 \%, 50 \%, 60 \%, 70 \%, 80 \%$ and $90 \%)$. Specifically, they are: Ten Global APE.B portfolios (equally weighted APE and Bond portfolio with varying S\&P 500 components), ten Global APE.G portfolios (equally weighted APE and Gold/Silver portfolio with varying S\&P 500 components), and ten Global APE.G.B portfolios (equally weighted APE, Gold/Silver, and Bond portfolio with varying S\&P 500 components).

Table 2 (Figure 2) presents the mean returns and standard deviations for the forty Global portfolios constructed in the study along with S\&P 500 over the period August 2002 through September 2010. Not surprisingly, S\&P 500 is positioned at the very bottom of the risk-return profiles in Figure 2; all the Global portfolios in the study yield higher returns than does S\&P 500. In addition, Figure 2 (Table 2) portrays that Global APE.B portfolios, bearing the lowest risk among all the portfolios (with standard deviations ranging from $3.23 \%$ to $4.4 \%$ ), are superior to S\&P 500 in terms of risk-return characteristics. However, the risk-return trade-offs of Global APE.B portfolios are not desirable since the returns are decreasing as risk increases. In Markowitz's mean-variance framework, a rational investor would prefer the portfolios with (a) the lowest risk for the same (or higher) return or (b) the highest return for the same (or lower) risk. Clearly, the only risk-return dominant Global APE.B portfolio is the one with $100 \%$ investment in the equally weighted APE and Bond portfolio, yielding .79\% return and 3.23\% standard deviation. Given that S\&P 500 delivers only .34\% return with $4.59 \%$ standard deviation over the same period, this Global APE.B portfolio may be very appealing to the investors, especially the ones with low risk tolerance level.

The evidence suggests that for these investors, the strategy of 50\% investment in Asia/Pacific/European stock markets and 50\% in the investment grade corporate bonds works well. Furthermore, Figure 2 (Table 2) displays that Global APE.G.B portfolios dominate Global APE portfolios. That is, Global APE.G.B portfolios yield higher returns at any given risk level than do Global APE portfolios. As the investment grade corporate bonds and gold/silver portfolios are less correlated with S\&P 500, resulting in considerable gains from diversification, the strategy of combining equity portfolios with Bond and Gold/Silver portfolios enhances the investments' risk-return profiles during the sample period. Additionally, Figure 2 (Table 2) illustrates that when the investment in S\&P 500 is $20 \%$ or less and the investment in the equally weighted APE and Gold/Silver portfolio is $80 \%$ or more, the Global APE.G portfolios are risk-return dominant with relatively high returns (ranging from $1.18 \%$ to $1.4 \%$ ). Unfortunately, these high returns come at some risk; standard deviations range from $5.98 \%$ to $6.8 \%$, which are the highest among all the Global portfolios in the sample. Thus, despite that all these Global APE.G portfolios are risk-return dominant, they may not be very attractive to the investors with low-to-medium risk tolerance due to the inherent high risk.

Moreover, Figure 2 (Table 2) indicates that when the investment risk is set at $4.92 \%$ standard deviation or lower, Global APE.G portfolios are inferior to Global APE.G.B portfolios. Apparently, the investment grade corporate bond portfolio plays a crucial role in risk diversification when it is incorporated into Global APE.G portfolios. Virtually, it is a risk reduction investment tool to decrease portfolio volatility and deliver more stable portfolio returns.

Finally, Figure 2 (Table 2) illustrates that when the investment in the equally weighted APE, Gold/Silver, and Bond portfolio is $60 \%$ or more and the investment in S\&P 500 is $40 \%$ or less, risk-return dominant Global APE.G.B portfolios are obtainable, with standard deviation ranging from $4.22 \%$ to $4.92 \%$ and return ranging from $.8 \%$ to $1.12 \%$. The evidence suggests that the investors with moderate risk tolerance should invest no more than 40\% in S\&P 500, and no less than 20\% in each of the following: Asia/Pacific/European stock market, Gold/Silver index fund, and the investment grade corporate bond fund. So far, a number of risk-return dominant Global portfolios are identified for the investors with various risk tolerance levels. It would be interesting to see whether the superior risk-return performances of these Global portfolios are statistically significant. 
Table 2: Mean Returns and Standard Deviations for Various Global Portfolios and S\&P 500 (August 2002-September 2010)

\begin{tabular}{|c|c|c|c|c|c|}
\hline & & & & & \\
\hline & $\%$ & ent in & & & \\
\hline Portfolio & US & APE/B/G & Mean Return & Standard Deviation & Count \\
\hline GLOBAL APE & $0 \%$ & $100 \%$ & $1.01 \%$ & $5.41 \%$ & 98 \\
\hline GLOBAL APE.B & $0 \%$ & $100 \%$ & $0.79 \%$ & $3.23 \%$ & 98 \\
\hline GLOBAL APE.G & $0 \%$ & $100 \%$ & $1.40 \%$ & $6.80 \%$ & 98 \\
\hline GLOBAL APE.G.B & $0 \%$ & $100 \%$ & $1.12 \%$ & $4.92 \%$ & 98 \\
\hline GLOBAL APE & $10 \%$ & $90 \%$ & $0.95 \%$ & $5.27 \%$ & 98 \\
\hline GLOBAL APE.B & $10 \%$ & $90 \%$ & $0.74 \%$ & $3.29 \%$ & 98 \\
\hline GLOBAL APE.G & $10 \%$ & $90 \%$ & $1.29 \%$ & $6.37 \%$ & 98 \\
\hline GLOBAL APE.G.B & $10 \%$ & $90 \%$ & $1.04 \%$ & $4.69 \%$ & 98 \\
\hline GLOBAL APE & $20 \%$ & $80 \%$ & $0.88 \%$ & $5.14 \%$ & 98 \\
\hline GLOBAL APE.B & $20 \%$ & $80 \%$ & $0.70 \%$ & $3.37 \%$ & 98 \\
\hline GLOBAL APE.G & $20 \%$ & $80 \%$ & $1.18 \%$ & $5.98 \%$ & 98 \\
\hline GLOBAL APE.G.B & $20 \%$ & $80 \%$ & $0.96 \%$ & $4.49 \%$ & 98 \\
\hline GLOBAL APE & $30 \%$ & $70 \%$ & $0.81 \%$ & $5.02 \%$ & 98 \\
\hline GLOBAL APE.B & $30 \%$ & $70 \%$ & $0.65 \%$ & $3.47 \%$ & 98 \\
\hline GLOBAL APE.G & $30 \%$ & $70 \%$ & $1.08 \%$ & $5.61 \%$ & 98 \\
\hline GLOBAL APE.G.B & $30 \%$ & $70 \%$ & $0.88 \%$ & $4.34 \%$ & 98 \\
\hline GLOBAL APE & $40 \%$ & $60 \%$ & $0.74 \%$ & $4.92 \%$ & 98 \\
\hline GLOBAL APE.B & $40 \%$ & $60 \%$ & $0.61 \%$ & $3.59 \%$ & 98 \\
\hline GLOBAL APE.G & $40 \%$ & $60 \%$ & $0.97 \%$ & $5.29 \%$ & 98 \\
\hline GLOBAL APE.G.B & $40 \%$ & $60 \%$ & $0.80 \%$ & $4.22 \%$ & 98 \\
\hline GLOBAL APE & $50 \%$ & $50 \%$ & $0.67 \%$ & $4.83 \%$ & 98 \\
\hline GLOBAL APE.B & $50 \%$ & $50 \%$ & $0.56 \%$ & $3.73 \%$ & 98 \\
\hline GLOBAL APE.G & $50 \%$ & $50 \%$ & $0.87 \%$ & $5.01 \%$ & 98 \\
\hline GLOBAL APE.G.B & $50 \%$ & $50 \%$ & $0.73 \%$ & $4.16 \%$ & 98 \\
\hline GLOBAL APE & $60 \%$ & $40 \%$ & $0.61 \%$ & $4.75 \%$ & 98 \\
\hline GLOBAL APE.B & $60 \%$ & $40 \%$ & $0.52 \%$ & $3.88 \%$ & 98 \\
\hline GLOBAL APE.G & $60 \%$ & $40 \%$ & $0.76 \%$ & $4.79 \%$ & 98 \\
\hline GLOBAL APE.G.B & $60 \%$ & $40 \%$ & $0.65 \%$ & $4.15 \%$ & 98 \\
\hline GLOBAL APE & $70 \%$ & $30 \%$ & $0.54 \%$ & $4.69 \%$ & 98 \\
\hline GLOBAL APE.B & $70 \%$ & $30 \%$ & $0.47 \%$ & $4.04 \%$ & 98 \\
\hline GLOBAL APE.G & $70 \%$ & $30 \%$ & $0.65 \%$ & $4.63 \%$ & 98 \\
\hline GLOBAL APE.G.B & $70 \%$ & $30 \%$ & $0.57 \%$ & $4.19 \%$ & 98 \\
\hline GLOBAL APE & $80 \%$ & $20 \%$ & $0.47 \%$ & $4.64 \%$ & 98 \\
\hline GLOBAL APE.B & $80 \%$ & $20 \%$ & $0.43 \%$ & $4.21 \%$ & 98 \\
\hline GLOBAL APE.G & $80 \%$ & $20 \%$ & $0.55 \%$ & $4.55 \%$ & 98 \\
\hline GLOBAL APE.G.B & $80 \%$ & $20 \%$ & $0.49 \%$ & $4.28 \%$ & 98 \\
\hline GLOBAL APE & $90 \%$ & $10 \%$ & $0.40 \%$ & $4.61 \%$ & 98 \\
\hline GLOBAL APE.B & $90 \%$ & $10 \%$ & $0.38 \%$ & $4.40 \%$ & 98 \\
\hline GLOBAL APE.G & $90 \%$ & $10 \%$ & $0.44 \%$ & $4.53 \%$ & 98 \\
\hline GLOBAL APE.G.B & $90 \%$ & $10 \%$ & $0.41 \%$ & $4.41 \%$ & 98 \\
\hline S\&P 500 & $100 \%$ & $0 \%$ & $0.34 \%$ & $4.59 \%$ & 98 \\
\hline
\end{tabular}

Notes:

Global APE portfolios consist of APE and S\&P 500.

Global APE.B portfolios consist of APE, Bond, and S\&P 500.

Global APE.G portfolios consist of APE, Gold/Silver, and S\&P 500.

Global APE.G.B portfolios consist of APE, Gold/Silver, Bond, and S\&P 500. 


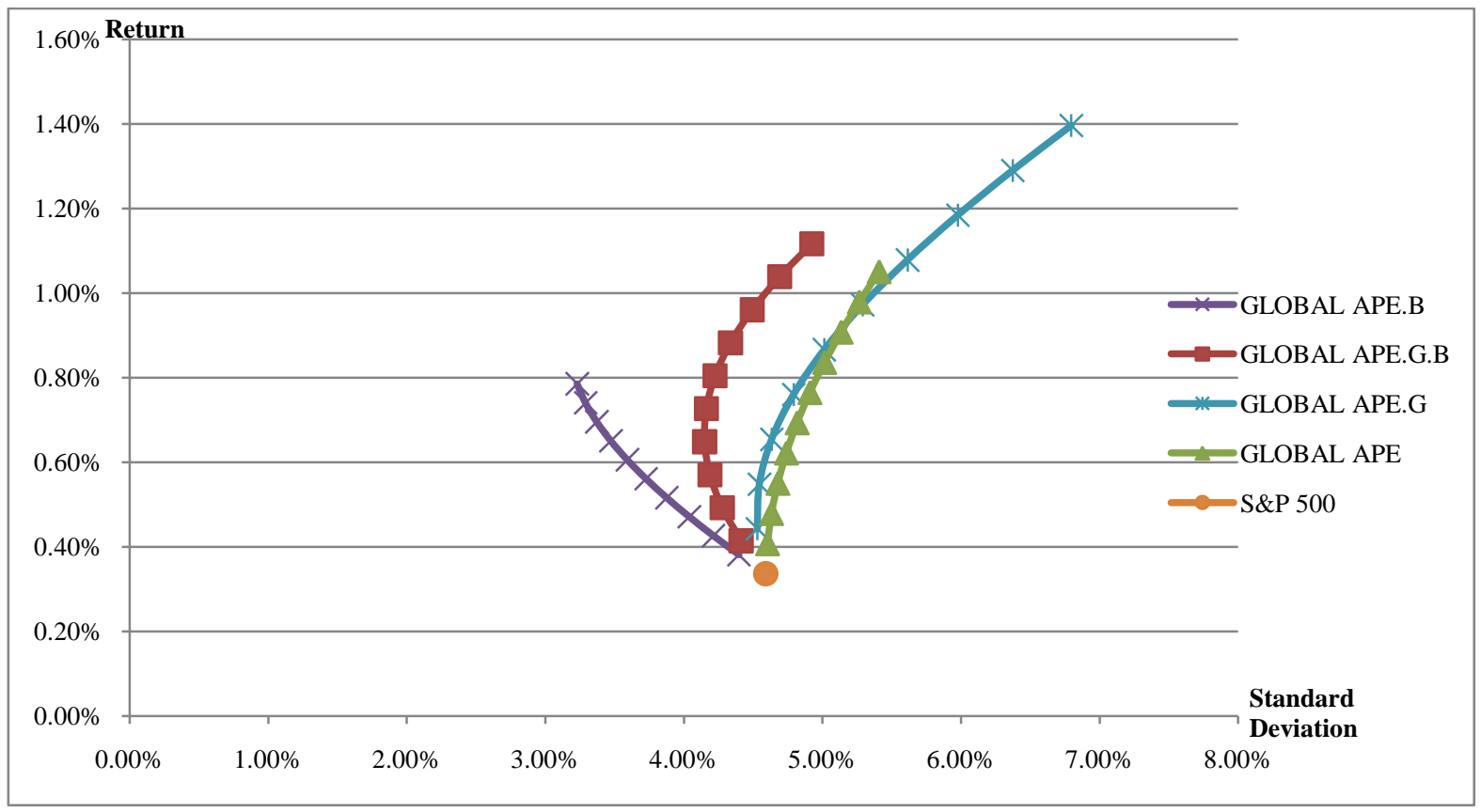

Figure 2: Risk-Return Profiles of Various Global Portfolios and S\&P 500 (August 2002-September 2010)

To address this issue, the Sharpe reward-to-volatility ratio is adopted to quantify the risk-return characteristics of a Global portfolio and the Sharpe spread, the difference in Sharpe ratio between a Global portfolio and S\&P 500, is employed to measure the superior performance of the portfolio. The one-month T-bill yield is used as the risk-free interest rate in computing the reward for bearing the investment risk, i.e., the return in excess of the T-bill rate to compensate the U.S. investors for taking the risk involved in the investments. The Sharpe performance measure is computed as the ratio of a portfolio's excess return over the sample period to the standard deviation of the returns over that period; it gives investment reward per unit of investment risk. The better the portfolio performs, the greater the risk-adjusted Sharpe ratio.

Table 3 presents the 36-month rolling mean Sharpe ratios for all of the forty Global portfolios over the period July 2005 to September 2010. To investigate whether there are improvements in the reward per unit of investment risk, the spreads in the 36-month rolling Sharpe ratios between the various global portfolios and S\&P 500 are computed. To examine whether the improvements in the Sharpe measures are statistically significant, $t-$ statistics are computed to test the hypothesis that the mean Sharpe spread is zero over the sample period. The results are summarized in Table 3. It is confirmed that, with or without Gold/Silver and/or Bond hedging, all the Global portfolios in the study outperform S\&P 500 over the sample period; the mean Sharpe spread between each of these Global portfolios and S\&P 500 is positive. This superior risk-adjusted performance as a result of global diversification ranges from a low of .0179 for Global APE.B with $90 \%$ investment in S\&P 500 and $10 \%$ in the equally weighted APE and Bond portfolio, to a high of .2006 for Global APE with 100\% invested in the equally weighted Asia/Pacific and European equity portfolio. In addition, the evidence in Table 3 indicates that for the vast majority of the Global portfolios, the superior performances are substantial and not completely random. In fact, the Sharpe spread between S\&P 500 and each of the risk-return dominant Global portfolios identified earlier in Figure 2 (Table 2) is statistically significant at the .005 level. 
Table 3: Differences in Rolling Sharpe Measures between Various Global Portfolios and S\&P 500 (July 2005-September 2010)

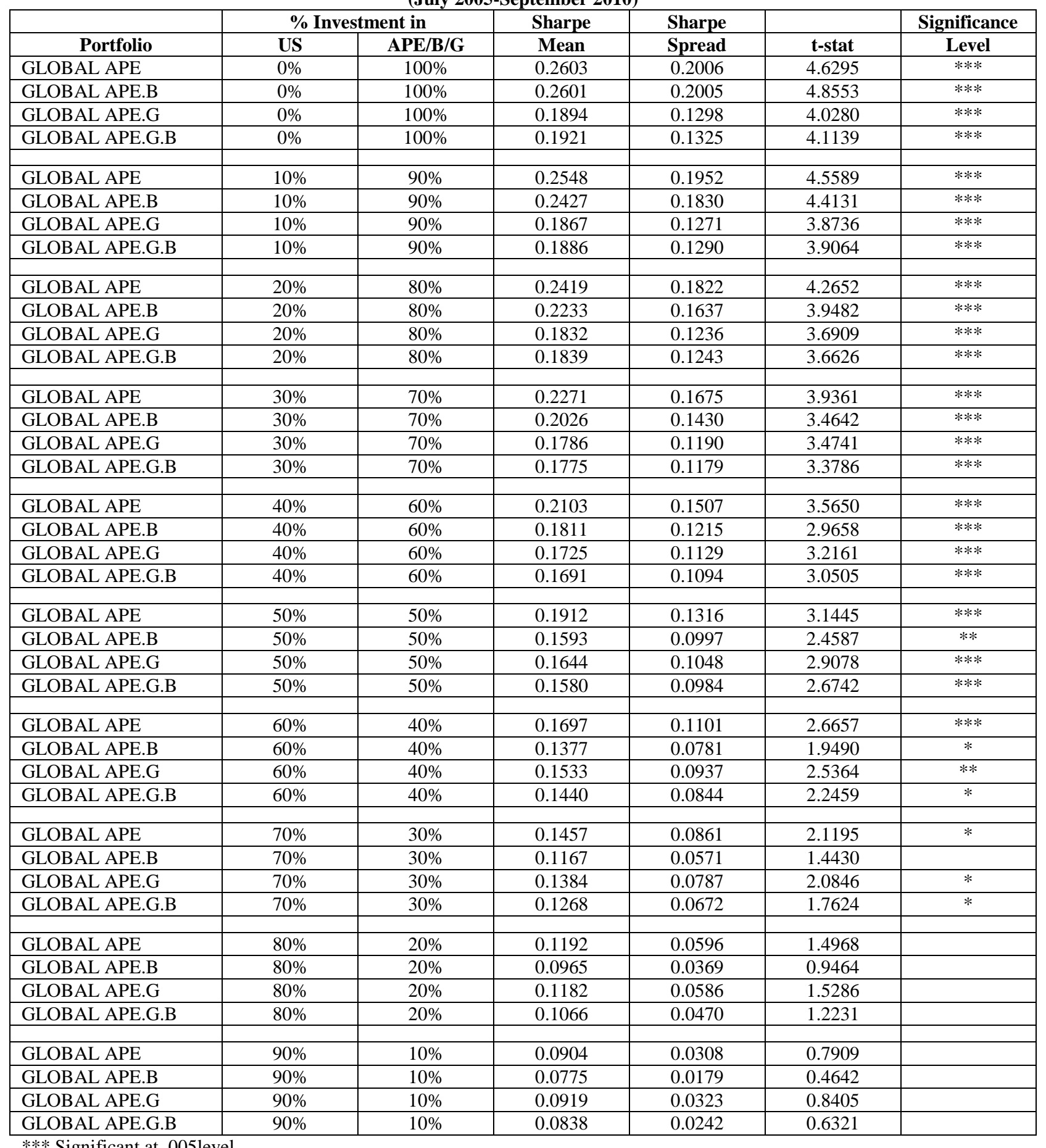

*** Significant at .005level.

** Significant at .01 level.

* Significant at .05 level. 


\section{CONCLUSION}

The findings of this study suggest that the increased interdependence of world stock markets does not eliminate the diversification benefits for the U.S. equity investors over the period August 2002 to September 2010; the gains from stock diversification into Asia/Pacific/European markets are very much intact. Furthermore, the evidence suggests that the hedging strategy of incorporating the investment grade corporate bonds and gold/silver index fund into the equity portfolios goes a long way over the sample period. The risk-return profiles of the Global portfolios are greatly improved, even after the global financial crisis of 2008-09. It is clear that the weak correlation between S\&P 500 and investment grade corporate bond and gold/silver portfolios provides considerable diversification gains to the U.S. investors over the study period. In conclusion, some allocation to these investment vehicles is essential for global equity investors seeking protections in today's volatile markets. The findings indicate the following important remarks:

1. The investors with very low risk tolerance should invest about 50\% in Asia/Pacific/European stock markets and $50 \%$ in the investment grade corporate bond fund.

2. The investors with very high risk tolerance should invest at least $40 \%$ in Asia/Pacific/European stock markets, $40 \%$ in Gold/Silver index fund, and no more than $20 \%$ in S\&P 500.

3. The investors with moderate risk tolerance should invest at least 30\% in Asia/Pacific/European stock markets, $15 \%$ in the investment grade corporate bonds fund, $15 \%$ in the Gold/Silver index fund, and no more than $40 \%$ in S\&P 500 .

The findings from this research have practical implications for both investors and portfolio managers interested in going global.

\section{AUTHOR INFORMATION}

H. Christine Hsu is a professor of finance at California State University, Chico. She has taught both graduate and undergraduate finance courses at Chico State since 1985. Her research interests include capital budgeting, security analysis \& portfolio management, and enterprise resource planning in financial management. Her research manuscripts are published in various refereed journals, including Journal of Financial Research, Financial Accountability and Management, Journal of Financial and Strategic Decisions, International Business \& Economics Research Journal, Review of Business Information Systems, Business Quest, among others. Email: chsu@csuchico.edu

\section{REFERENCES}

1. Chang, T. and S. Caudill, "A Note on the Long-Run Benefits from International Equity Diversification for a Taiwan Investor Diversifying in the US Equity Market." International Review of Financial Analysis (2006): 57-67.

2. Chiou, W., A. Lee, and C. Chang, "Do Investors Still Benefit from International Diversification with Investment Constraints?" Quarterly Review of Economics and Finance (May 2009): 448-483.

3. Driessen, J., Laeven, L., "International Portfolio Diversification Benefits: Crosscountry Evidence from a Local Perspective." Journal of Banking and Finance (2007): 1693-1712.

4. Fletcher, J. and A. Marshall, "An Empirical Examination of the Benefits of International Diversification." Journal of International Financial Markets, Institutions and Money (December 2005): 455-468.

5. Gupta, R. and G. Donleavy, "Benefits of Diversifying Investments into Emerging Markets with TimeVarying Correlations: An Australian Perspective.” Journal of Multinational Financial Management (2009): 160-177.

6. Markowitz, H. M., "Portfolio Selection,” Journal of Finance (1952): 77-91.

7. Metghalchi, M. and V. Adamchik, "The Performance of the European Stock Indices." The Business Review (Summer 2009): 68-73.

8. $\quad$ Sharpe, W.F., Mutual Fund Performance. Journal of Business (1966): 119-138.

9. Solnik, B., "Why Not Diversify Internationally Rather Than Domestically?” Financial Analysts Journal (July/August 1974): 48-54. 
10. Solnik, B., C. Bourcrelle and Y. L. Fur, "International Market Correlation and Volatility." Financial Analysts Journal (September/October 1996): 17-34.

11. You, L. and R. Daigler, "The Strength and Source of Asymmetric International Diversification." Journal of Economics and Finance (July 2010): 349-364. 
NOTES 